\title{
Analysis of Causal Factors of Accidents near Mahipalpur Junction on NH-8 in Delhi
}

\author{
Nirpinder Jain ${ }^{1}$, Bharat Bhushan Jindal ${ }^{2}$ \\ ${ }^{1,2}$ (Research Scholar, IK Gujral Punjab Technical University, Kapurthala, Punjab, India) \\ ${ }_{2}^{2}$ (Associate Professor, Department of Civil Engineering, MM University Sadopur Ambala, India)
}

\begin{abstract}
Road accidents cause more than 1,35,000 deaths in India every year which is higher than any other country in the world. Increasing motorization without adequate institutional mechanism is a major cause of this problem. Although, the number of fatalities caused by road accidents in Delhi has been declining over the years, but the situation is still alarming. In this paper a study has been carried out on road accident data of Mahipalpur junction, an entry point to T-3 Airport in Delhi. A $1.8 \mathrm{~km}$ road stretch was selected, traffic and road accident data of three years (2012-2014) was collected and the trends were analyzed. The accidents have taken place primarily in three locations Viz. in front of Radisson Hotel, near Mahipalpur Junction, and in Service road and Flyover towards Dhaulakuan. A few accidents have taken place in some odd locations.
\end{abstract}

Keywords - Black Spot, Accident, Road Users

\section{INTRODUCTION}

The highway network is accelerated at a fast rate and the safety of vehicular movements becomes a concern for everybody due to reporting of loss of lives and properties along with fatal injuries and periodical obstruction of traffic flow. National highways provide the efficient mobility and accessibility function. The increasing road accidents have created social problems due to loss of lives and human miseries. Road accidents are essentially caused by interactions of the vehicles, road users and roadway conditions. Each of these basic elements comprises a number of sub elements like pavement characteristics, traffic characteristics, road user's behavior, vehicle design, driver's characteristics and environmental aspects.

\section{Blackspot}

The term black spot is used to describe locations that have a higher average accident rate [2]. The identification, analysis and treatment of road crash black spots are widely regarded as one of the most effective approaches to road crash prevention. Black Spot could be at intersection, mid block section of the road with a proven history of high crash density. Generally hazardous locations are selected on the basis of formal road safety audits.

\section{METHODOLOGY}

Road accident data has been collected from the respective police stations. Major accident prone locations (Black Spots) have been identified based on the number of accidents, severity of accidents and number of fatalities. Field surveys were conducted using total station to collect the geometric features of the black spots. The reasons for the accidents are studied and analyzed [1]. 


\section{DATA COLLECTION AND ANALYSIS}

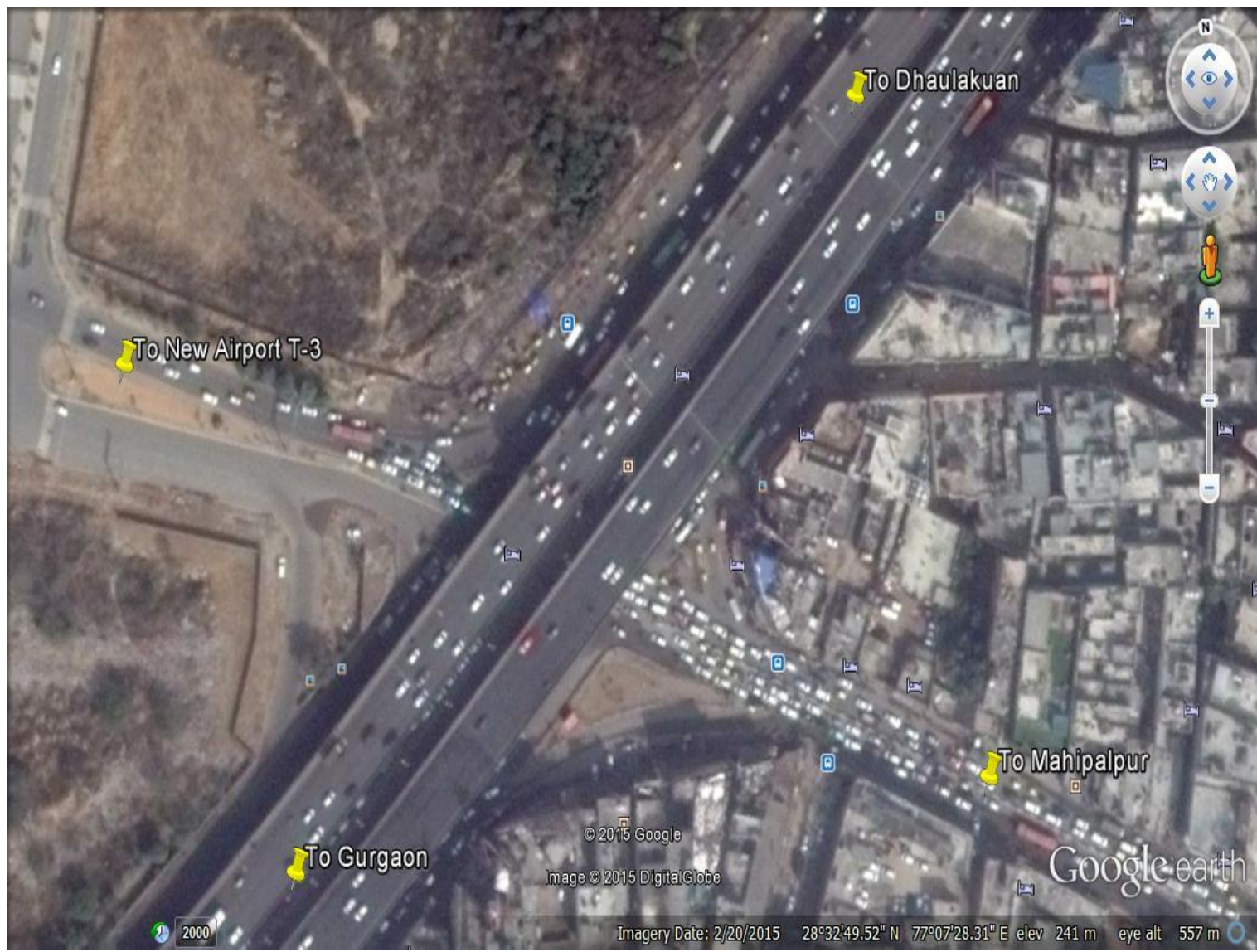

Fig 1: An Aerial View of Mahipalpur Junction As Seen In Early 2015 Showing Traffic Concentration

Table I. Summary of Accidents in 3 Years from 2012 To 2014

\begin{tabular}{|c|c|c|c|c|c|c|c|c|c|}
\hline \multirow{2}{*}{\multicolumn{2}{|c|}{ Description }} & \multicolumn{2}{|c|}{2012} & \multicolumn{2}{|c|}{2013} & \multicolumn{2}{|c|}{2014} & \multicolumn{2}{|c|}{$\begin{array}{c}2015 \\
\text { (From Jan-June) }\end{array}$} \\
\hline & & & & & & & & Total & $\%$ \\
\hline \multicolumn{2}{|l|}{ Total Accidents } & 25 & & 19 & & 26 & & 11 & \\
\hline \multirow{2}{*}{ Types of Accidents } & Fatal & 8 & 32 & 3 & 16 & 7 & 27 & 3 & 27 \\
\hline & Non-fatal & 17 & 68 & 16 & 84 & 19 & 73 & 8 & 73 \\
\hline Accidents during Day & & 6 & 24 & 5 & 26 & 11 & 42 & & \\
\hline Accidents during Night & & 19 & 76 & 14 & 74 & 15 & 58 & & \\
\hline \multirow[t]{4}{*}{ Vehicle Type } & Pvt. Car/ SC \& MC & 8 & 32 & 7 & 37 & 8 & 31 & & \\
\hline & $\begin{array}{l}\text { Tempo/ Mini/ Bus/ } \\
\text { Delivery Van/ Tractor }\end{array}$ & 2 & 8 & 1 & 5 & 4 & 15 & & \\
\hline & HTV/ GDS/ BUS & 5 & 20 & 7 & 37 & 4 & 15 & & \\
\hline & Unknown & 10 & 40 & 4 & 21 & 10 & 39 & & \\
\hline
\end{tabular}

The Pie Chart of this data is presented in the following figure. 

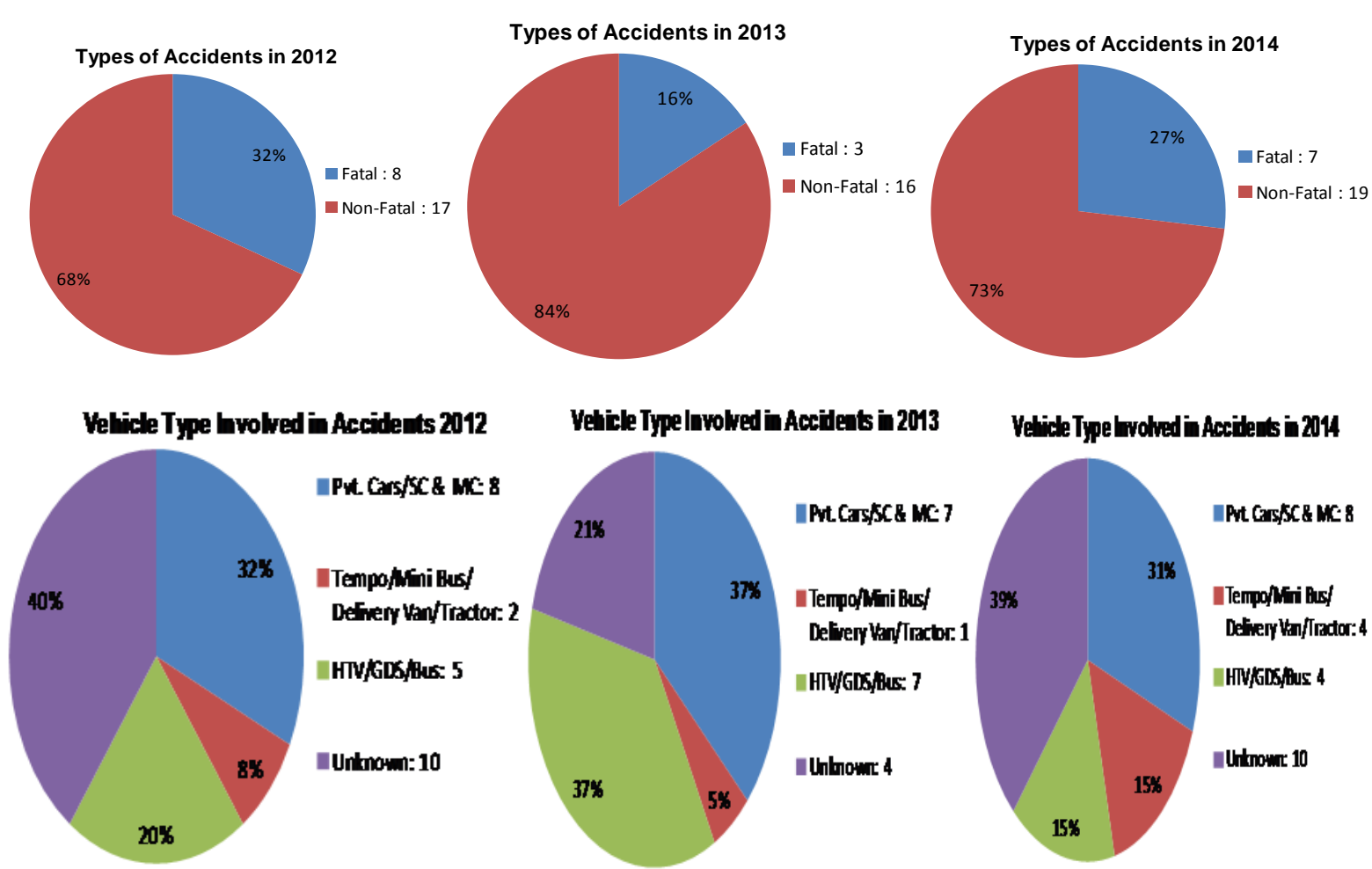

Fig. 2: Pie Charts of Accidents Data

The accident data has been presented in the form of Pie Charts in Fig.1 for easy understanding the effect of various factors vs. the number of accidents:

\section{TREND OF ACCIDENT RATE}

From the accident data of 2012, 2013 and 2014 as presented in table 1, it can be seen that the number of accidents were 25,19 and 26 respectively. The accidents were marginally less in the year 2013 but it had shot up in the year 2014 .

\section{FATAL VS. NON-FATAL ACCIDENTS}

Percentage of fatal accidents in these 3 years has decreased from $32 \%$ to $27 \%$ steadily whereas rate of non-fatal accidents had increased from $68 \%$ to $84 \%$ (in 2013).

\section{RATE OF ACCIDENTS DURING DAY AND NIGHT}

It is observed that majority of accidents have taken place in the night in all the 3 years from 2012 to 2014. In the night the accident percentage is ranging from 58\% to $76 \%$ suggesting vehicles moving in night are involved in more number of accidents than during day. The accidents during day were in the range of $24 \%$ to $42 \%$. It may be noted that long-distance trucks are prevented to enter Delhi during day-time and they enter Delhi only during night which may be one of the reasons.

\section{TYPE OF VEHICLES INVOLVED IN ACCIDENTS}

Lighter vehicles like cars and heavier vehicles like Trucks are seen to be contributing to a greater extent to accidents from the data given in Table 1. Besides, many unknown vehicles are reported to be responsible for accidents suggesting that these accidents could have happened in the night involving cars or Trucks. 


\section{ACCIDENT LOCATIONS}

The accidents have taken place primarily in three locations Viz. in front of Radisson Hotel, near Mahipalpur Junction, and in Service road and Flyover towards Dhaulakuan. A few accidents have taken place in some odd locations. The effort must be to improve the following spots:

i) On Service road in front of Radisson Hotel

ii) At Mahipalpur Junction (at Red Light and nearby places)

iii) Service road and Flyover towards Dhaulakuan/Dwaraka

The numbers of accidents which have taken place at the above three critical locations are given in Table II

Table I. Major Accident Locations

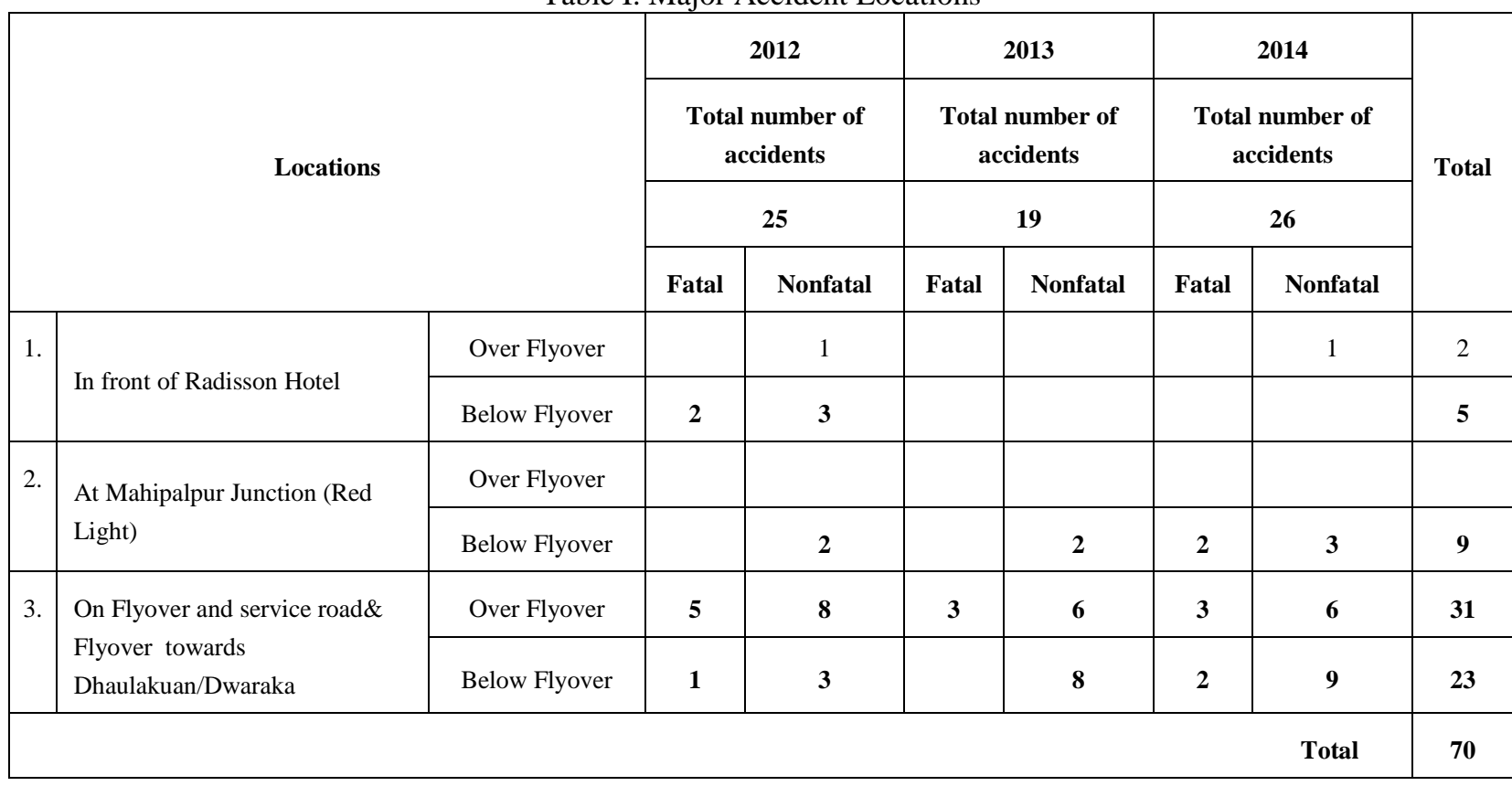

The data has been presented in the form of Pi Charts in Fig. 2 for better understanding.

Total number of Accidents in 2012 (Over \& Below Flyover)

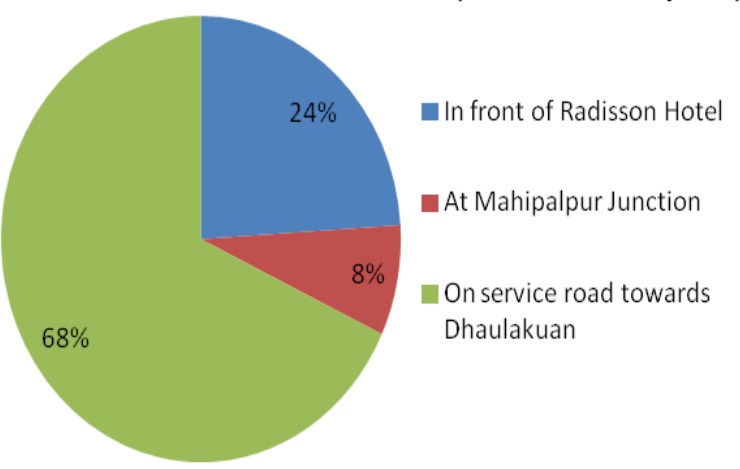

Total number of Accidents in 2013

(Over \& Below Flyover)

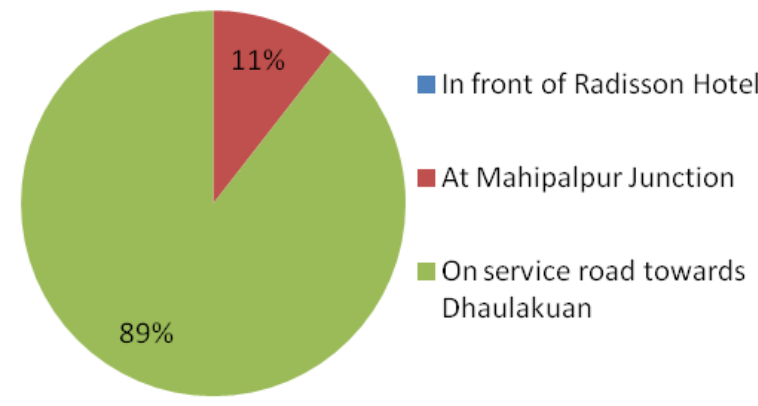




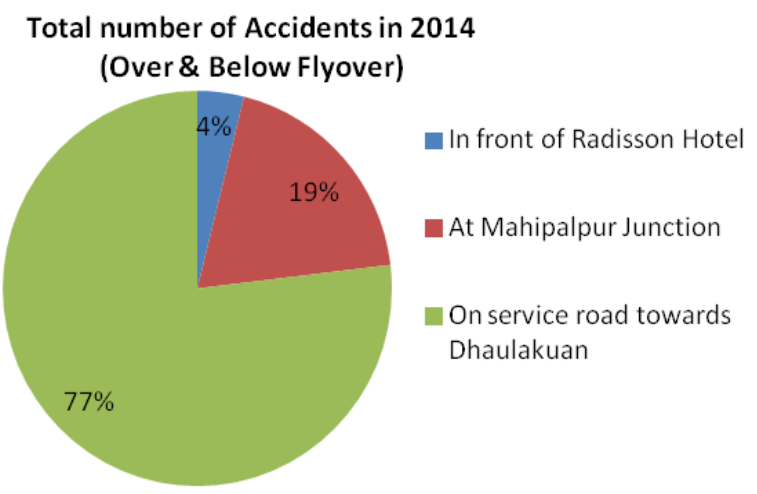

Fig.3: Pie Chart showing \% of accidents taking place at various locations

\section{Discussion of the Data Presented In Table 2}

From the 3 year's accident data given in Table 2, it is seen that 70 accidents have taken place both at ground and top of Flyover. About 26\% accidents of these accidents were fatal. From data shown, the concentration of accidents is seen to be primarily in front of three locations viz., i) in front of Radisson Hotel where 7 accidents have taken place, ii) at Mahipalpur Junction where 9 accidents have taken place and iii) on Flyover and service road towards Dhaulakuan/Dwaraka where 54 accidents have taken place. Out of 54 accidents, 23 accidents had taken place on service roads whereas 31 accidents had taken place on Flyovers. The same data when 3 years data is clubbed is shown in Fig. 3. The causes of accidents are on account of speeding vehicles, lane indiscipline and deficiencies in geometric features of islands, median openings, narrow road width, motorists driving in wrong direction, lack of acceleration and deceleration lanes, etc. As a matter of fact, the number of accidents in signalised Mahipalpur Junction and near Radisson Hotels is relatively less.

Total number of Accidents in 2012, 2013 \& 2014

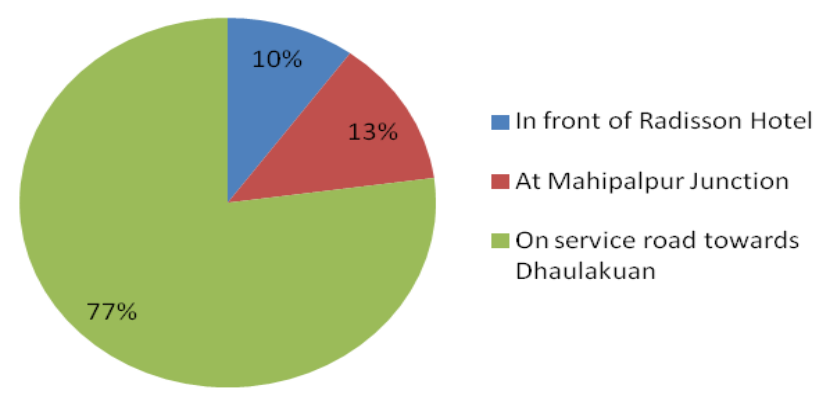

Fig.4: Pie Chart showing \% of accidents at various locations in 3 years

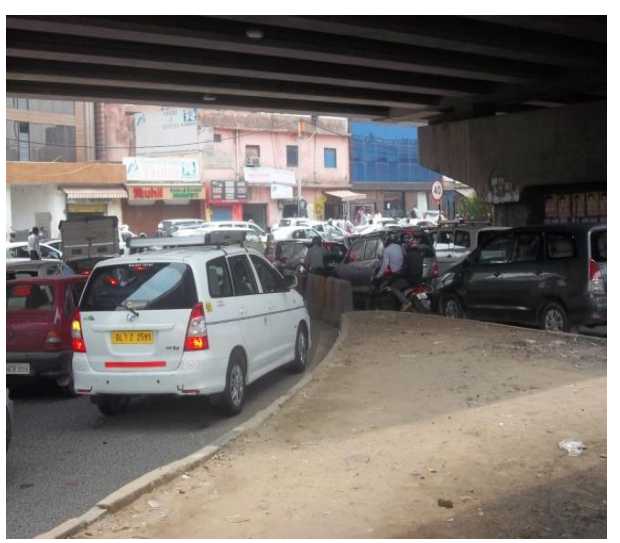

Fig 5: Merging traffic to Gurgaon and traffic taking U-Turn

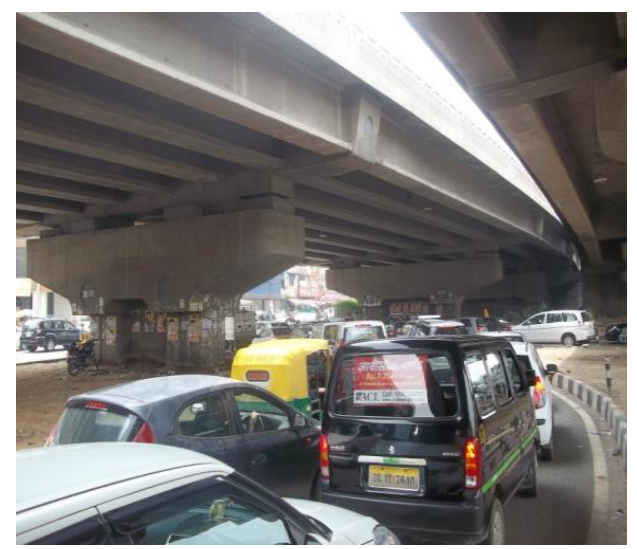

Fig 6: Congestion at merging traffic in Front of Radisson Hotel 


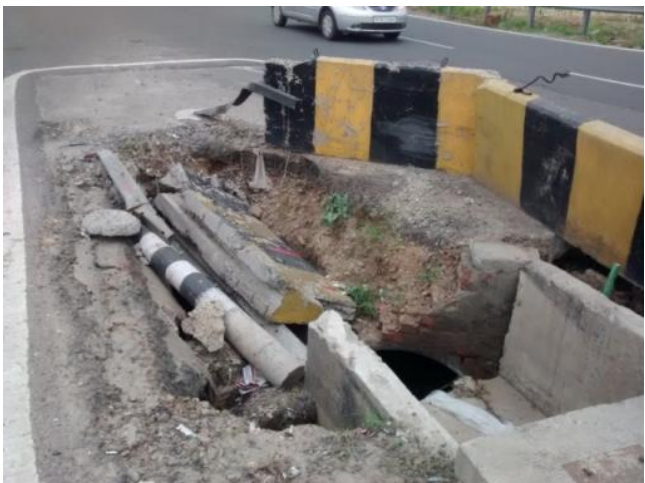

Fig 7: Dangerous Island with open drain

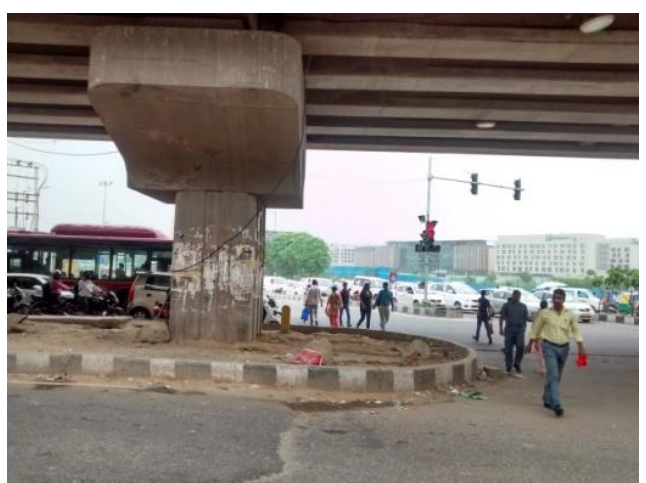

Fig 8: Unpaved Median Nose

\section{IMPROVEMENT MEASURES}

i) To dismantle all old islands and to construct new islands, kerb, medians especially at the entrance to Airport Road and Mahipalpur side.

ii) To construct new pavement in patches where islands have been shifted.

iii) To install new signages like hazard marker etc.

iv) To shift and improve all noses of medians.

v) Speed breakers to be provided.

vi) To pave the medians in junction area and islands with coloured concrete paver blocks.

\section{CONCLUSIONS}

The study presented has been conducted to identify the accident prone locations on the selected and analyze the causing factors of accidents. The following are the main conclusions drawn from the study:

(i) No deceleration lane has been provided for the safety of traffic from Gurgaon turning towards New Airport/Aerocity.

(ii) The road layout towards Airport from junction needs to be properly planned to take care of large volume of traffic using it.

(iii) As it is one of the entry points to Delhi's prestigious Indira Gandhi International Airport, T-3, there is a need to improve the aesthetic appeal of this junction with greenery/ flower beds etc.

(iv) Provision of speed breakers on service roads is necessary on and pick and drop facility on the approach ramp of grade separator needs to be monitored.

The Authors are Thankful to Late Dr L.R Kadiyali, for his guidance, data sharing and motivation.

\section{REFERENCES}

[1] Kadiyali L.R and N.B Lal "Principles of Highway Engineering", 4th edition Khanna Publishers, Delhi 2006.

[2] Sikka Sushant (2014), "Prediction of Road Accidents in Delhi using Back Propagation Neural Network Model", IJCSET

[3] Dr. SSSV Gopala Raju, Apparao. G, P. Mallikarjunareddy (2013), "Identification Of Accident Black Spots For National Highway Using GIS”, International Journal of Scientific \& Technology Research Volume 2, Issue 2, February 2013.

[4] Dr Parida M, P.K Singh, Dr S.S Jain (2011), “ Road Safety Audit for Four Lane National Highways”, 3rd International Conference on Road Safety and Simulation, Indianapolis, US 